Background Pirfenidone and Nintedanib have been approved by NICE with the aim of attenuating progression and extending the prognosis for patients with IPF. There are no indications as to which should be used first line.

Aim Because neither Pirfenidone nor Nintedanib are intended to be curative, to investigate the effects of either drug on patients' quality of life, and to evaluate the patients' perspectives on their use in the management of IPF as a whole.

Method 15 patients were monitored over an 8 month period, and a patient story was compiled. Forced vital capacity was monitored as an indicator of the drugs clinical efficacy (a rate of decline that did not exceed $10 \%$ in 12 months). Then the patients' perspective on how treatment(s) affected their quality of life was evaluated; this included physical wellbeing, psychological wellbeing and any adversities associated with the drug (s). Weight was also monitored. Results were obtained through use of patient notes and verbal feedback during appointments. Results In no case did a patient's FVC decline greater than $10 \%$ in a 12 month period, suggesting Pirfenidone and Nintedanib were clinically effective in all cases. It was inconclusive what impact the drugs had on physical wellbeing, however both drugs improved patients' psychological wellbeing. Pirfenidone was associated with profound weight loss, anorexia, rash, constipation, nausea, dyspepsia, migraine, cough, hypersomnia and altered taste. All patients receiving Pirfenidone experienced at least one side effect. All eight patients

Abstract M21 Table 1 Treatment regimen of each patient involved in the study (this includes note of treatments that were discontinued).

\begin{tabular}{|c|c|c|c|c|c|}
\hline Reference & Gender & P irfenidone & Nintedanib & $\begin{array}{c}\text { Pulmonary } \\
\text { Rehabilitation }\end{array}$ & $\begin{array}{c}\text { Application for } \\
\text { Transplant }\end{array}$ \\
\hline A & $\therefore$ & $x$ & & & \\
\hline B & $\therefore$ & $x$ & $s$ & & \\
\hline C & $\therefore$ & & $x$ & $x$ & \\
\hline D & $\therefore$ & & $\checkmark$ & $s$ & \\
\hline $\mathrm{E}$ & $\therefore$ & $x$ & $\downarrow$ & , & \\
\hline F & $\therefore$ & $x$ & $\checkmark$ & $r$ & \\
\hline G & $\therefore$ & $x$ & & & \\
\hline $\mathrm{H}$ & ${ }^{2}$ & & $s$ & & \\
\hline I & $\circ$ & $x$ & $x$ & & \\
\hline J & 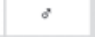 & & $x$ & & \\
\hline $\mathrm{K}$ & $\therefore$ & & 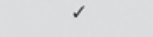 & s & Rejected \\
\hline L & $\therefore$ & & $s$ & & \\
\hline M & $\therefore$ & $x$ & $x$ & & \\
\hline $\mathrm{N}$ & 8 & $x$ & $x$ & s & Accepted \\
\hline 0 & $\circ$ & & $x$ & $x$ & Rejected \\
\hline & $\begin{array}{l}13 \text { males } \\
\text { and } 2 \\
\text { females } \\
\text { were } \\
\text { involved } \\
\text { in the } \\
\text { study }\end{array}$ & $\begin{array}{l}8 / 8 \text { patients } \\
\text { discontinued } \\
\text { treatment } \\
\text { with } \\
\text { Pirfenidone }\end{array}$ & $\begin{array}{l}6 / 13 \text { patients } \\
\text { discontinued } \\
\text { treatment } \\
\text { with } \\
\text { Nintedanib. } \\
7 \text { patients } \\
\text { were } \\
\text { to le rating } \\
\text { therapy } \\
\text { including } 1 \text { at } \\
\text { a reduced } \\
\text { dose }\end{array}$ & $\begin{array}{l}5 \text { patients } \\
\text { completed } \\
\text { Pulmonary } \\
\text { Rehabilitation. } \\
2 \text { had to } \\
\text { dis continue } \\
\text { formedical } \\
\text { reasons. }\end{array}$ & $\begin{array}{l}3 \text { patients } \\
\text { applied for } \\
\text { transplant. } 1 \text { is } \\
\text { on the waiting } \\
\text { list. } 1 \text { was } \\
\text { declined for } \\
\text { deteriorating } \\
\text { too quickly; the } \\
\text { other was } \\
\text { rejected for } \\
\text { being too well. }\end{array}$ \\
\hline \multicolumn{6}{|c|}{$J=$ receiving therapy } \\
\hline \multicolumn{6}{|c|}{$x=d$ is continued treatment } \\
\hline \multicolumn{6}{|c|}{$\downarrow=$ receiving a reduced dose } \\
\hline
\end{tabular}

discontinued treatment due to adversities. Nintedanib was associated with diarrhoea, impaired liver function, weight loss, fatigue, anorexia, arrhythmia and epistaxis. 6 out of 13 patients discontinued treatment due to adversities, however other patients reported no adversities whatsoever.

Conclusions Although both drugs were considered clinically effective, Nintedanib was tolerated in the majority without impairing quality of life, indicating the benefits have the potential to outweigh its risks. However because $100 \%$ of patients discontinued Pirfenidone due to adverse effects, the question regarding whether the benefits outweigh its adversities ideally needs to be re-addressed on a larger scale. This study is therefore in favour of Nintedanib being used first line should larger studies reflect a similar outcome.

\section{M22 DOES TELEPHONING PATIENTS BEFORE THE DIFFICULT- TO-TREAT ASTHMA CLINIC IMPROVE ATTENDANCE?}

S Oliveira, R Robinson, S Mault, B McDonough, H James, H Joplin, G Jones, J Blakey, H Burhan. Royal Liverpool and Broadgreen University Hospital Trust, Liverpool, UK

\subsection{6/thoraxjnl-2017-210983.444}

Aims To assess the use of telephone reminders in a difficultto-treat asthma service on:

1) clinic attendance rates

2) the prevalence of poor concordance

Background Non attendance at clinics leads to increased pressure on NHS resources and cost the NHS £3225 million in 2012 2013. Our trust has an opt-in appointment text message reminder service - despite which, the did-not-attend (DNA) rate at our tertiary asthma clinic was $\geq 20 \%$ in 2016 . It is known that up to $30 \%$ of patients attending tertiary asthma services have poor adherence with their asthma medication. ${ }^{1}$ We were interested in establishing whether directly telephoning patients prior to review would allow us to impact DNA rate and simultaneously identify non-concordant individuals that might be redirected to specialist pharmacy input prior to clinical review.

Methods During a 3 month period [Feb-Apr 2017] we telephoned patients $\geq 1$ week prior to their scheduled appointment - in total 3 attempts were made to contact an individual. During successful contacts express permission was sought to access electronic prescription fulfilment data.

Results Successful contact was made with 53.4\% [66/126] patients - 41 did not answer, 19 had no valid contact details. The majority of those contacted [54/66] agreed to an adherence check but only $n=37$ had been registered on the electronic prescription fulfilment system, of these 51\% [19/37] had an asthma medication pick-up rate $<80 \%$. Of those successfully contacted $n=64 / 66$ attended their appointment which compared favourably to the overall DNA rate during the same period in 2016 [3.0\% vs $17.5 \% ; \mathrm{p}=<0.05]$. Although we managed to perform a compliance check on less than a third of the total cohort [37/122], our telephone system allowed $\geq 1$ in 6 patients [19/122]to be directed to a dedicated specialist pharmacist led clinics (focussing on optimising concordance/education) thus creating additional capacity in our difficult-to-treat asthma service.

Conclusion Telephoning patients prior to clinic was associated with a substantial reduction in DNAs, and identified individuals that could benefit from a targeted intervention around concordance. The health economics of the intervention need further evaluation. 


\section{REFERENCE}

1. Robinson et al. Systematic assessment of difficult-to-treat asthma. ERJ 2003, September;22(3):478-83.

\section{M23 INTEGRATED RESPIRATORY CARE TRAINING FROM THE TRAINEE'S PERSPECTIVE: MIND THE GAP}

${ }^{1} \mathrm{~A}$ Jayadev, ${ }^{2} \mathrm{Z}$ Pond, ${ }^{3} \mathrm{~L}$ Preston, ${ }^{4} \mathrm{H}$ Ward. ${ }^{1}$ Homerton University Hospital, London, UK; ${ }^{2}$ University Hospital Southampton, Southampton, UK; ${ }^{3}$ British Thoracic Society, London, UK;

${ }^{4}$ New Cross Hospital , Wolverhampton, UK

\subsection{6/thoraxjn-2017-210983.445}

Introduction Postgraduate education needs to incorporate more training in community based settings for the '5 Year Forward View' to become a reality. A BTS members survey in 2013 found $62 \%$ of respondents agreed integrated respiratory physicians added value, and a subsequent report identified that embedding integrated care into training would be key. ${ }^{1,2}$ We surveyed the views of respiratory registrars to understand the current national training opportunities available in integrated respiratory care.

Methods The BTS Models of Care committee designed and distributed a questionnaire to trainee members in May 2017.

Results 81 trainees responded (43\% male; $87 \%$ working full time). The sample was representative with responses from all but one region. $80 \%$ of trainees participating were $\geq \mathrm{ST} 5$. $60 \%$ had not received any integrated respiratory care training and of those that had (figure 1);29\% described a single training episode (talk or clinic), 21\% attended a one day session, $42 \%$ described regular training episodes, e.g., MDT and 2\% had organised a placement themselves in an integrated care team for $\geq 1$ week. $90 \%$ of trainees felt it would be beneficial to have more integrated care experience. Key themes identified included a lack of clear definition of integrated care and an appreciation of the increasing relevance of this training.
Challenges identified include lack of training opportunities and incorporation into an already full curriculum.

Conclusions Despite 90\% of respondents wanting more experience and $77 \%$ considering, in part, some integrated respiratory work in their consultant job plan, only $40 \%$ had received any formal training of which $50 \%$ had only 1 day. This may be due in part to the 'poor definition' of integrated care which appears to be a persistent common theme. One of the future tasks of the BTS Models of Care Committee will be to provide guidance in developing and delivering programmes of training in Integrated care for Respiratory trainees.

\section{REFERENCES}

1. Roberts NJ et al. P34. what is integrated care and what is the value of an integrated respiratory specialist? BTS Abstracts 2013, Winter Meeting.

2. BTS Report. Role of the respiratory specialist in integrated care teams 2014 http://www.brit-thoracic.org.uk

\section{Idiopathic pulmonary fibrosis treatment update}

\section{M24 DO ANTIFIBROTICS IMPACT ON LUNG TRANSPLANTATION OUTCOMES IN IDIOPATHIC PULMONARY FIBROSIS?}

${ }^{1}$ YK Huong, ${ }^{2} \mathrm{~V}$ Dhunnoo, ${ }^{1} \mathrm{C}$ Leonard, ${ }^{1} \mathrm{R}$ Venkateswaran, ${ }^{1} \mathrm{~N}$ Chaudhuri. ${ }^{1}$ University Hospital of South Manchester, Manchester, UK; ${ }^{2}$ University of Manchester, Manchester, UK

10.1136/thoraxjnl-2017-210983.446

Introduction Antifibrotics slow progression of forced vital capacity (FVC) in patients with moderate Idiopathic Pulmonary Fibrosis (IPF) (FVC 50\%-80\%). ${ }^{1,2}$ Lung transplantation (LTx) is also a management option in a small cohort of patients who meet stringent eligibility criteria. With increased

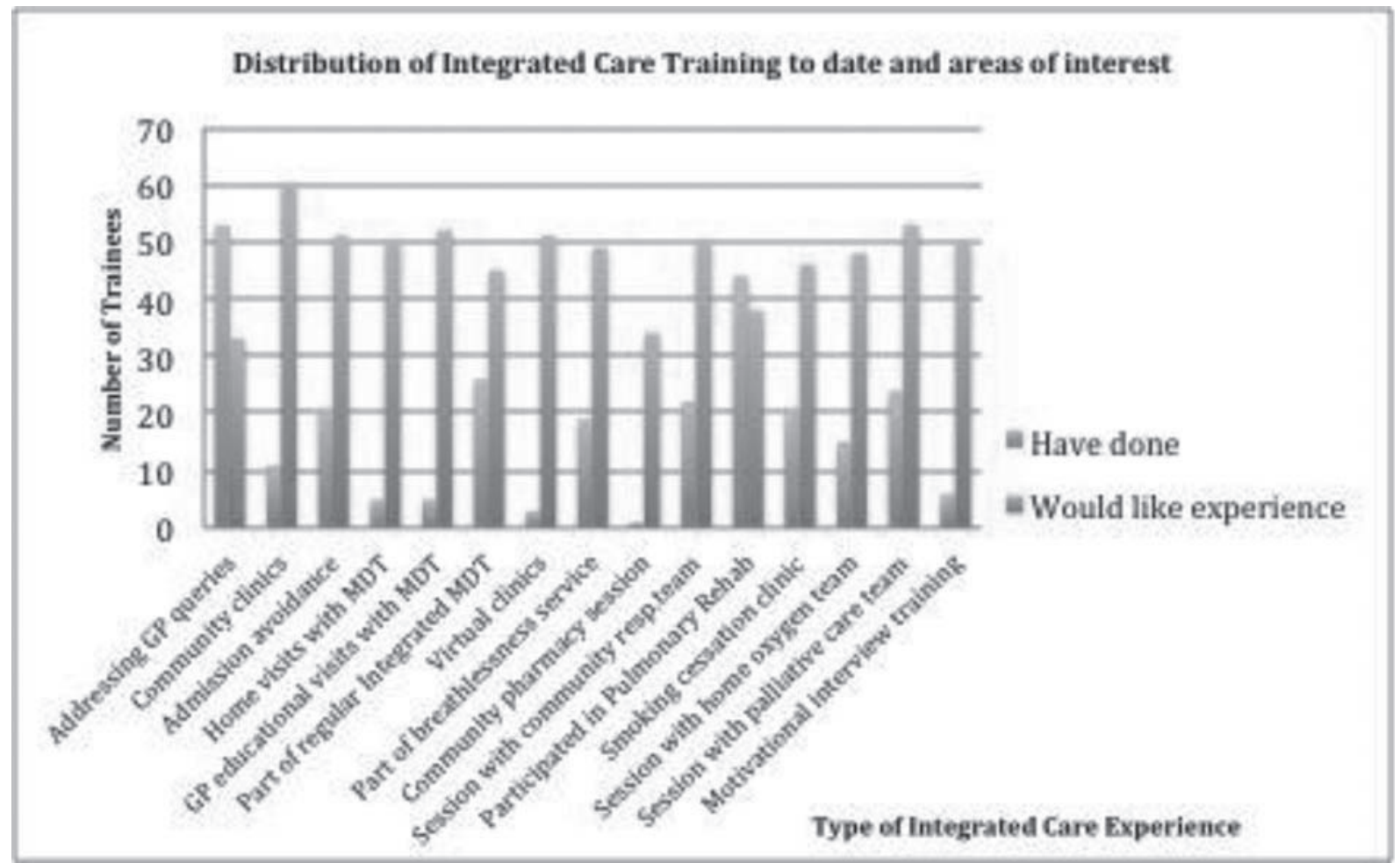

